\title{
Imaging High-Resolution Structure of GFP-Expressing Neurons in Neocortex In Vivo
}

\author{
Brian E. Chen, ${ }^{1}$ Balazs Lendvai, ${ }^{1,2}$ Esther A. Nimchinsky, ${ }^{1}$ Barry Burbach, ${ }^{1}$ \\ Kevin Fox, ${ }^{3}$ and Karel Svoboda ${ }^{1,4}$ \\ ${ }^{1}$ Howard Hughes Medical Institute, Cold Spring Harbor Laboratory, Cold Spring Harbor, New York 11724, USA; ${ }^{2}$ Institute of Experimental \\ Medicine, Hungarian Academy of Sciences, 1083 Budapest, Hungary; ${ }^{3}$ Cardiff School of Biosciences, Cardiff University, Cardiff CF1 3US, Wales, \\ United Kingdom
}

\begin{abstract}
To detect subtle changes in neuronal morphology in response to changes in experience, one must image neurons at high resolution in vivo over time scales of minutes to days. We accomplished this by infecting postmitotic neurons in rat and mouse barrel cortex with a Sindbis virus carrying the gene for enhanced green fluorescent protein. Visualized with 2-photon excitation laser scanning microscopy, infected neurons showed bright fluorescence that was distributed homogeneously throughout the cell, including axonal and dendritic arbors. Single dendritic spines could routinely be resolved and their morphological dynamics visualized. Viral infection and imaging were achieved throughout postnatal development up to early adulthood (P 8-30), although the viral efficiency of infection decreased with age. This relatively noninvasive method for fluorescent labeling and imaging of neurons allows the study of morphological dynamics of neocortical neurons and their circuits in vivo.
\end{abstract}

Sensory experience and the resulting patterns of coordinated neural activity help to organize neural circuits throughout the brain (Wiesel 1982; Katz and Shatz 1996). Changes in experience lead to reorganization of the structure of neocortical sensory maps (Kleinschmidt et al. 1987; Fox 1992; Katz and Shatz 1996). The underlying changes in microcircuitry are thought to be reflected in the morphology of individual neurons (Harris and Woolsey 1981; Antonini and Stryker 1993; Catalano et al. 1995) and their synapses (Greenough et al. 1985; Bailey and Kandel 1993). Relatively little is known about the relationships between changes at the level of maps and neurons. Similarly, little is known about the role of activity in the development and maintenance of dendritic and axonal morphologies in mammalian systems. In the hippocampus, a number of studies have addressed whether long-term potentiation produces structural changes at the level of dendritic spines, but these studies have produced inconsistent results (Van Harreveld and Fifkova 1975; Fifkova and Van Harreveld 1977; Desmond and Levy 1986; Desmond and Levy 1990; Sorra and Harris 1998). Studies in developing cultured brain slices (Dailey and Smith 1996; Maletic-Savatic et al. 1999) and cultures (Ziv and Smith 1996; Fischer et al. 1998) from hippocampal area CA1 show that dendritic protrusions can be structurally dynamic. Focal synaptic stimulation can produce growth of small dendritic protrusions in slice cultures

${ }^{4}$ Corresponding author.

E-MAIL svoboda@cshl.org; FAX (516) 367-8866.

Article and publication are at www.learnmem.org/cgi/doi/ $10.1101 / \mathrm{lm} .32700$.
(Engert and Bonhoeffer 1999; Maletic-Savatic et al. 1999); this growth is long lasting, input specific, and dependent on activation of synaptic NMDA receptors. Thus dendritic growth could be crucial in establishing synaptic connections during development, paving the way for the development of mature spines (Saito et al. 1992; Dailey and Smith 1996; Ziv and Smith 1996; Fiala et al. 1998). Such processes could underlie Hebbian plasticity during development and during the acquisition of memories in the adult brain.

However, these observations of dendritic morphological dynamics were made in cultured in vitro preparations, and it is difficult to assess the relevance of these studies to the situation in the intact brain. In organotypic slice cultures, for example, some properties of neurons and networks fail to develop normally, such as maturation of astrocytes (Gähwiler et al. 1997). In addition, neuronal morphogenesis depends on a variety of factors that are difficult to reproduce in vitro, such as the pattern of neuronal activity (McAllister et al. 1996; Maletic-Savatic et al. 1999), the presence of neurotrophins (McAllister et al. 1995; McAllister et al. 1997), and neuromodulatory systems. Thus, despite the convenience of the brain slice preparation, it is essential to also study activity and experience-dependent morphogenesis in the intact brain (Lendvai et al. 2000).

High-resolution imaging in intact neural tissues has traditionally been hindered by the degradation of resolution and contrast due to severe scattering of light. The invention of 2-photon laser scanning microscopy (2PLSM) (Denk et al. 1990) has largely overcome the problem of scattering, allowing high-resolution imaging of neuronal structure and function in intact nervous tissues, including in the mamma-

LEARNING \& MEMORY 7:433-441 @ 2000 by Cold Spring Harbor Laboratory Press ISSN1072-0502/00 \$5.00

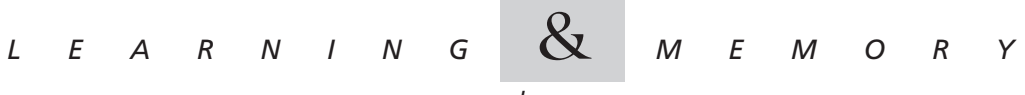

$$
\begin{aligned}
& \text { www.learnmem.org }
\end{aligned}
$$


lian neocortex in vivo (Denk and Svoboda 1997; Svoboda et al. 2000). 2PLSM produces high signal levels and low levels of photodamage, which is especially important when imaging living neurons over extended periods. This technique is therefore well suited to detect experience-dependent morphological plasticity. However, so far in vivo 2PLSM imaging has been limited to imaging neurons filled with synthetic dyes introduced through intracellular recording electrodes (Svoboda et al. 1997, 1999). This labeling technique is technically difficult, allows labeling of neurons only one at a time, and carries a high risk of damaging the cell. Bulk labeling techniques by using AM-ester (Yuste and Katz 1991) and dextran (O'Malley et al. 1996) derivatives of synthetic dyes have been successful only in selected preparations. In addition, synthetic dyes leak out of neurons, photobleach at high rates, and produce phototoxicity.

The problem of dye delivery can be overcome by using the gene for green fluorescent protein (GFP) (Chalfie et al. 1994) and its variants (Cormack et al. 1996; Heim and Tsien 1996). Delivery of GFP to mammalian neurons in intact tissues has been achieved with a variety of methods. In brain slices, foreign genes, including GFP, have been introduced by using biolistic gene transfer (Lo et al. 1994) and viral transfection by using adenovirus (Moriyoshi et al. 1996), vaccinia virus (Pettit et al. 1995), and Sindbis virus (Maletic-Savatic et al. 1999). It has also been shown that adenovirus (Moriyoshi et al. 1996) and Sindbis (Gwag et al. 1998 ) vectors can be used for gene transfer in neocortex in vivo. We use a replication-defective, neurotropic, recombinant Sindbis virus (SIN-EGFP) (Corsini et al. 1996) that was engineered to express enhanced GFP (EGFP) (Corsini et al. 1996; Maletic-Savatic et al. 1999; Malinow et al. 2000; Lendvai et al. 2000). Here we show that SIN-EGFP can be used to infect neurons efficiently in the neocortex of rats and mice throughout postnatal development. Infected neurons produce EGFP at high concentrations and remain viable for 1 wk after infection. GFPs are bright fluorophores under 2-photon excitation (Potter et al. 1996; Xu et al. 1996), appear to be quite resistant to photobleaching (Pierce et al. 1997), and produce minimal phototoxicity. EGFP-labeling together with 2PLSM thus allows high-resolution imaging over extended periods of time in vivo.

\section{RESULTS}

Rats and mice were anesthetized and surgically prepared for injections. Glass micropipettes (tip diameter $\sim 12 \mu \mathrm{m}$ ) were used to inject a suspension of SIN-EGFP virus directly into the extracellular space of barrel cortex in all layers. Several days after infection (1-7 d), we examined the vicinity of the injection site in sections of fixed tissue. The virus infected clusters of tens to thousands of neurons (Fig. 1A), recognizable by bright green fluorescence. Infection was limited to neurons, with no apparent infection of glia. The fluores-

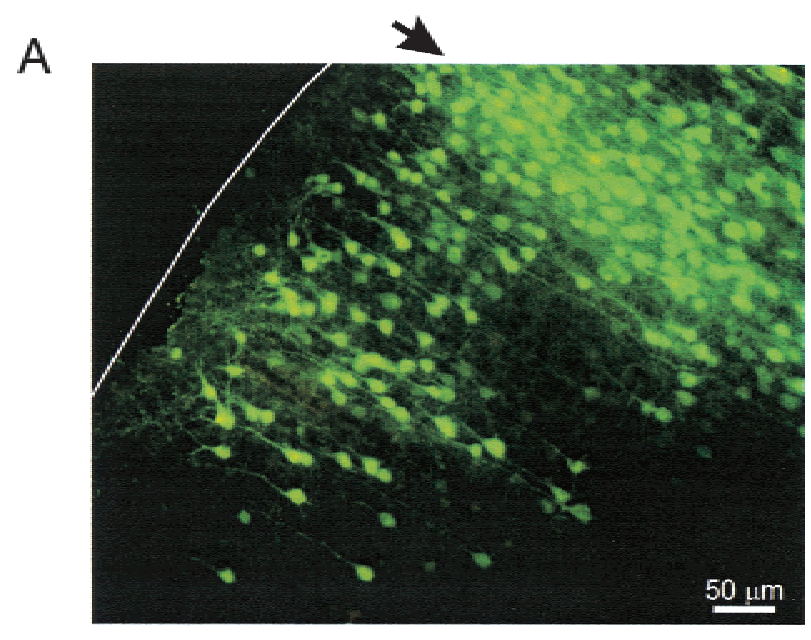

B
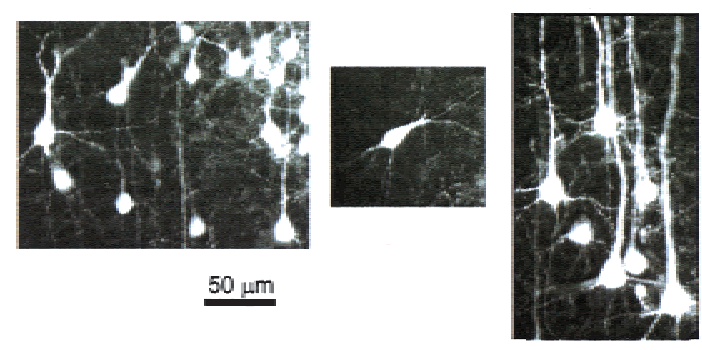

C

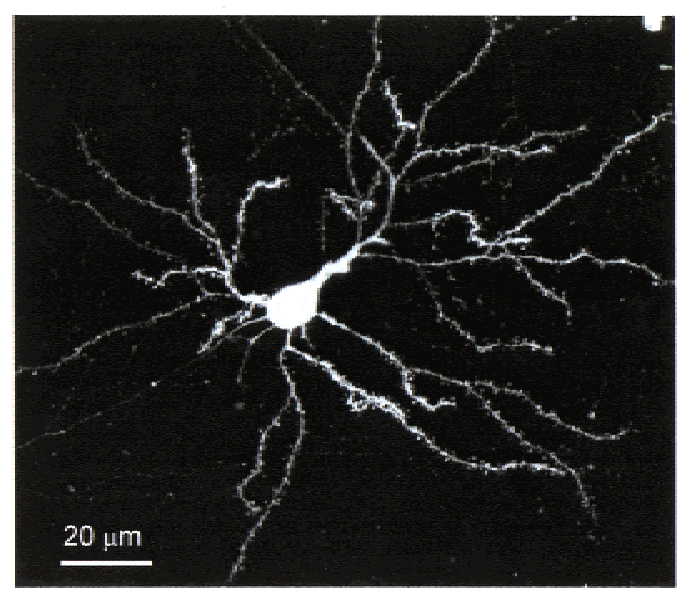

Figure 1 Rat neocortical neurons infected with recombinant Sindbis virus-enhanced green fluorescent protein in vivo imaged in fixed tissue sections. (A) Image of the injection site (arrow) and surrounding area (postnatal day $[\mathrm{P}] 11$ ). (B) Higher magnification images (P 14). Left, layer 2/3 pyramidal neurons. Middle, layer 5 interneuron. Right, layer 5 pyramidal neurons. (C) 2-photon laser scanning microscopy image of a layer 2 pyramidal neuron in a section from a mouse (P 36).

cence signal was distributed homogeneously throughout neurons (Fig. 1B), with no preferential staining of intracellular organelles. Fluorescence signals increased between 1 and $2 \mathrm{~d}$ of expression. The EGFP fluorescence survived

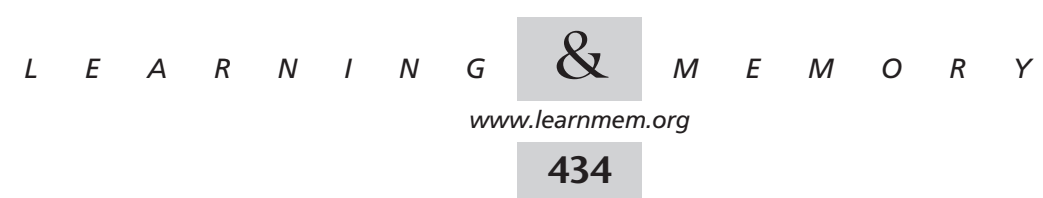


formaldehyde fixation, but the signals were diminished compared with those in living tissue (see below).

Infected neurons were distributed over a large volume of cortical tissue (Fig. 2A). Although the majority of infected neurons were in the vicinity (within $200 \mu \mathrm{m}$ ) of the injection site, a considerable fraction could be found up to 500 $\mu \mathrm{m}$ away. Neurons in this region of sparse labeling were ideal for high-resolution, low background in vivo imaging (Lendvai et al. 2000). Small numbers of neurons could even be seen several millimeters from the injection site, for example in the contralateral hemisphere and in thalamus (Fig.

A

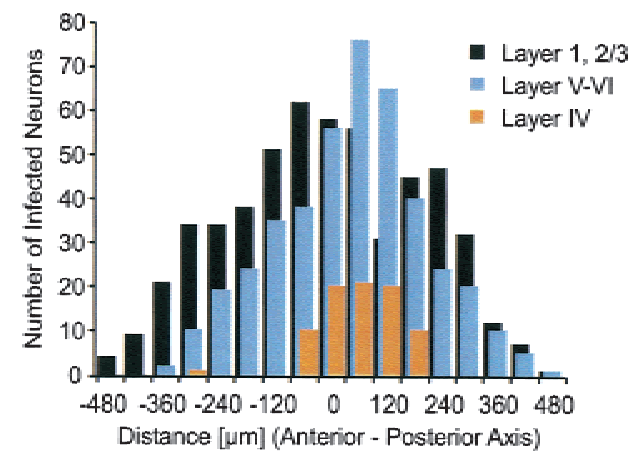

B
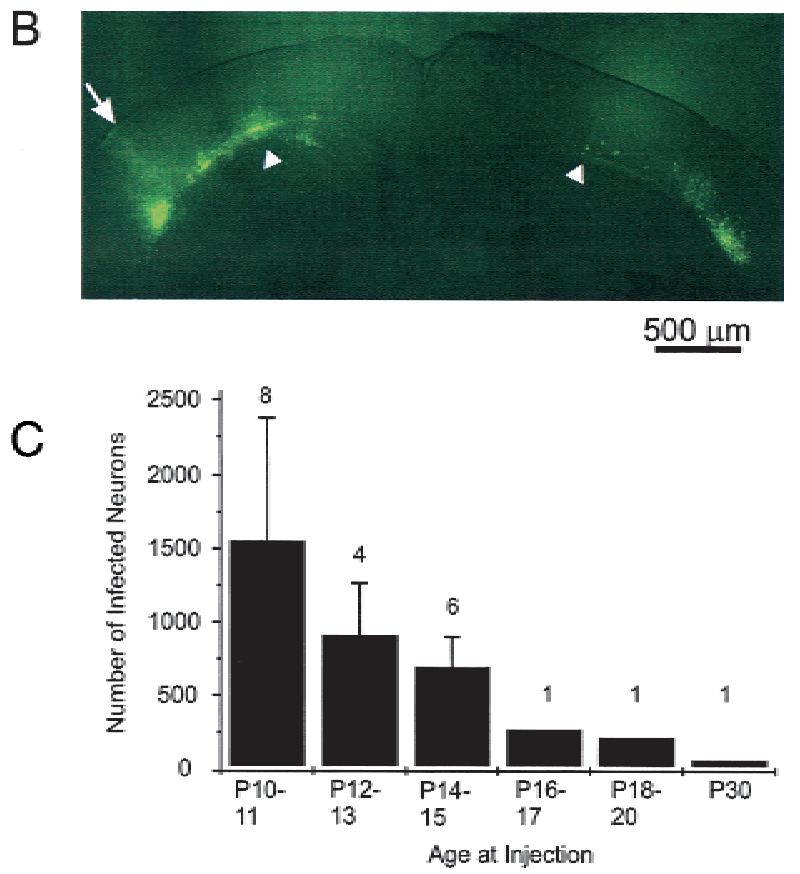

Figure 2 Properties of in vivo recombinant Sindbis virus enhanced green fluorescent protein infection in rat. (A) Typical spatial distribution of infected neurons (postnatal day [P] 14 at injection, 1 -d expression; number of infected cells $=1049$ ). (B) Photomontage showing the injection site (arrow) and clusters of infected neurons (arrowheads), also in the contralateral hemisphere (mouse $P$ 7). (C) Number of infected cells as a function of age (mean \pm SEM). Number of rats per group is indicated above the corresponding bar.
2B), suggesting that SIN-EGFP can infect neurons via axons. Infection was not only limited to young tissue, but was also achieved in relatively mature brains (up to P 30). However, using consistent infection protocols, the infection efficiency decreased markedly with age (Fig. 2C). The reasons for this decrease are not clear. No effort was made to infect neurons in rats older than P30 or in mice older than P56. Although the number of infected neurons was related to the volume of viral suspension injected, the trial-to-trial variability was large (Fig. 2C).

In an effort to characterize the impact on neocortical tissue of the insult from the injection and the infection with SIN-EGFP, we examined Nissl-stained tissue in the vicinity of the injection site. Sections of infected regions of the brain did not show signs of necrosis (Fig. 3). There was no evidence of gliosis; closer examination revealed no pyknotic nuclei. We also prepared acute neocortical brain slices from infected brains. Infected neurons maintained their bright EGFP fluorescence in brain slices and showed typical neocortical morphologies under 2PLSM (Fig. 4). Similarly, infrared differential interference contrast imaging of the tissue did not reveal obvious abnormalities in the infected brain slice regions (data not shown).

Because our primary goal was to use EGFP fluorescence to study the structural dynamics of dendrites in vivo, we were concerned about the possibility that the virus itself produces cytoskeletal rearrangements and abnormal morphology. In particular, it has been reported that the nonstructural Sindbis protein NSP1 can produce filopodia-like protrusions in HeLa and other cultured cells and disturbs the organization of the actin cytoskeleton (Laakkonen et al. 1998). To investigate if such perturbations occur in our system, we compared dendritic morphologies of neurons infected SIN-EGFP in vivo with neurons from the same slice that were labeled in fixed uninfected tissue with $\mathrm{DiO}$, a fluorescent membrane dye. Dendrites were imaged by using 2PLSM for both of the labeling techniques, and the density of dendritic protrusions was measured. These experiments showed that SIN-EGFP does not induce dendritic protrusions (densities of protrusions: $\mathrm{DiO}, 0.41 \pm 0.02 \mu \mathrm{m}^{-1}$; SINEGFP, $0.38 \pm 0.02 \mu \mathrm{m}^{-1}$, mean $\pm \mathrm{SEM} ; N=4$ ).

The study of neuronal motility and morphogenesis requires time-lapse high-resolution imaging in the intact brain. EGFP labeling together with 2PLSM proved ideal for this task. Labeled neurons produced extremely bright signal levels in vivo (compare Fig. 1C with Fig. 5). Somata, axons, dendrites, and their spines could easily be detected. To study spine morphological dynamics, we imaged dendrites of infected neurons repeatedly at 10 -min intervals. We found that dendritic morphology is extremely dynamic on time scales of minutes (Maletic-Savatic et al. 1999). For example, spines were seen to appear, disappear, and change shape (Fig. 5C).

High-resolution imaging in the intact brain can be perturbed by movements due to heartbeat and breathing. The

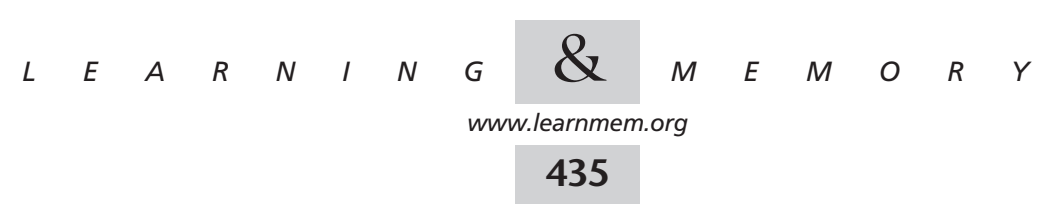



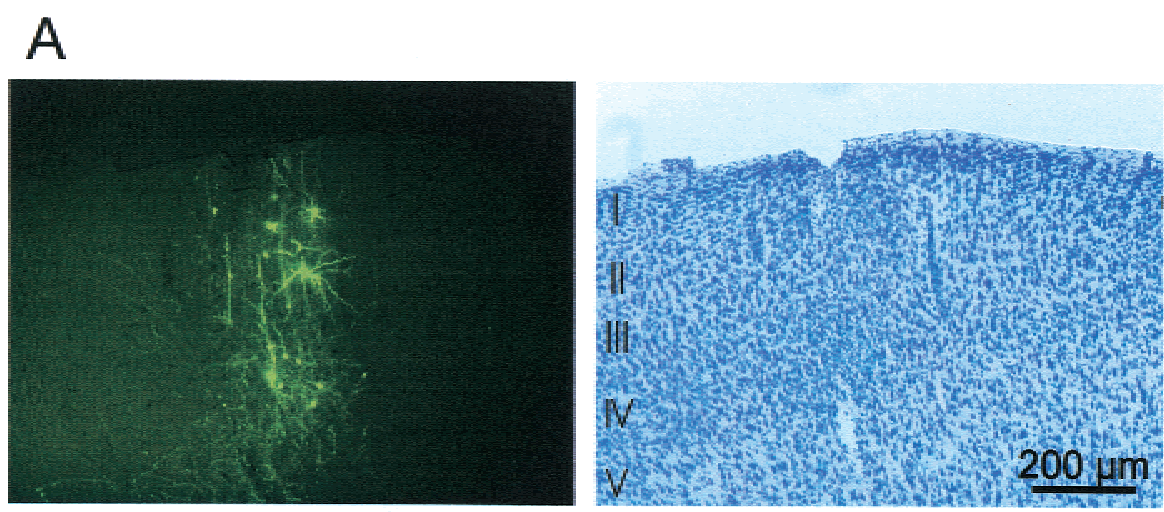

B
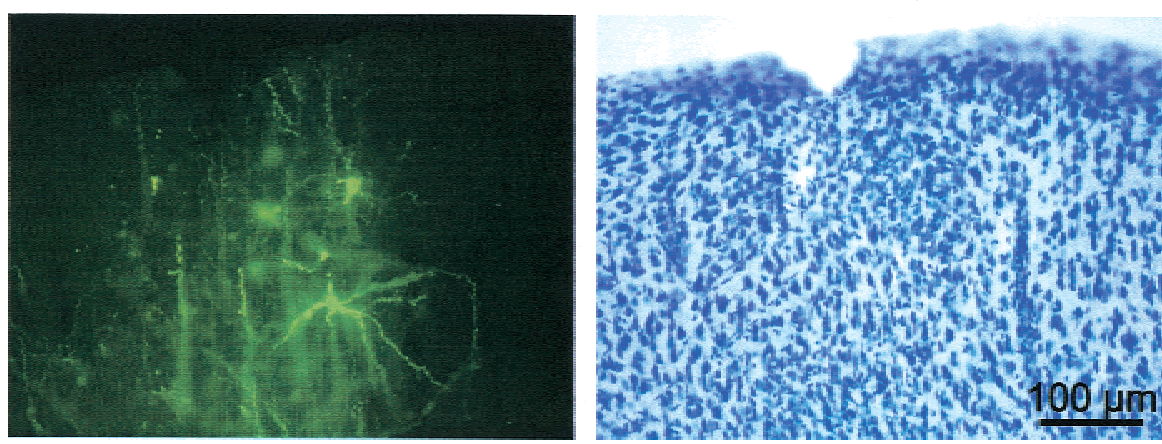

Figure 3 Comparison of fluorescence (left) and brightfield (right) images of Nissl-stained sections of rat neocortex. (A) Low magnification image showing laminar distribution of labeled cells. $(B)$ Higher magnification image showing absence of gliosis.

agar and coverslide on the brain together minimize these movements (Svoboda et al. 2000). To characterize possible artifacts associated with breathing or heartbeat, we imaged individual dendritic segments rapidly (20-100-sec intervals). These sampling intervals are sufficiently long to produce displacement due to breathing $(\sim 2 \mathrm{~Hz})$ or heartbeat $(\sim 5 \mathrm{~Hz})$. However, these intervals are fast on the scale of morphological rearrangements $(\sim 10 \mathrm{~min})$. We find that spine length changed very little over $20 \mathrm{sec}$ $(0.1 \pm 0.02 \mu \mathrm{m}$ per $20 \mathrm{sec})$. Similar control experiments have been published elsewhere (Lendvai et al. 2000). Furthermore, spines appeared and disappeared along the same dendrite at different times (Fig. 6), inconsistent with artifacts due to large-scale movement. Finally, spine motility measured in brain slices imaged at short time intervals showed similar types of movement (Fig. 6). It is therefore unlikely that artifacts due to heartbeat and breathing contribute significantly to measurements of dendritic motility in vivo.
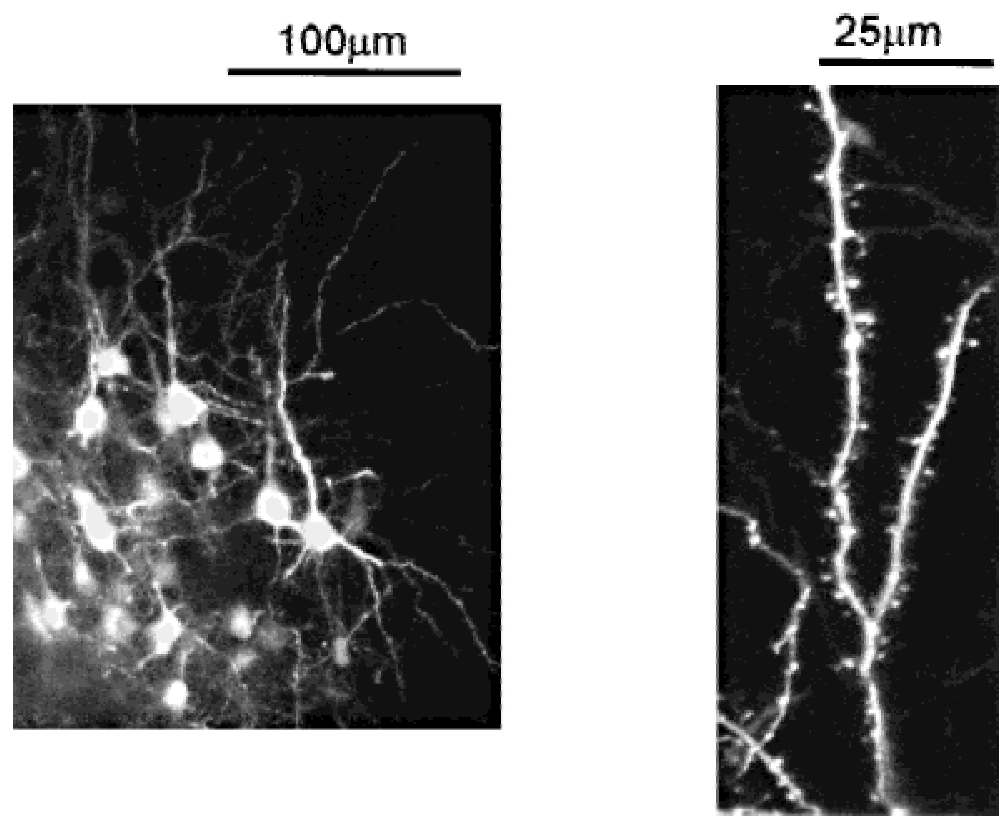

Figure 4 2-photon laser scanning microscopy images of recombinant Sindbis virus- enhanced green fluorescent protein-infected neurons in acute rat brain slices. Left, image at the edge of the injection site. Right, high-resolution image of a spiny dendritic segment.
The induction of experiencedependent plasticity in barrel cortex requires hours to days of altered sensory experience (Diamond et al. 1994; Glazewski and Fox 1996). To explore the morphological correlates of experience-dependent neocortical plasticity over such long times requires imaging neurons in animals prepared for chronic experiments. A photograph was taken of the brain's surface to mark positions of imaged neurons by using the local vasculature as landmarks. The animal was allowed to recover from anesthesia and explore its environment for 1 or $2 \mathrm{~d}$. Subsequently, it was prepared for a second imaging session. The same neuron could easily be found from the marked (previously taken) photograph and identified on the basis of its dendritic morphology. The high-resolution dendritic structure could then be imaged over days $(N=6$; Fig. 7). An increase in fluorescence was observed over several days, re- 
A
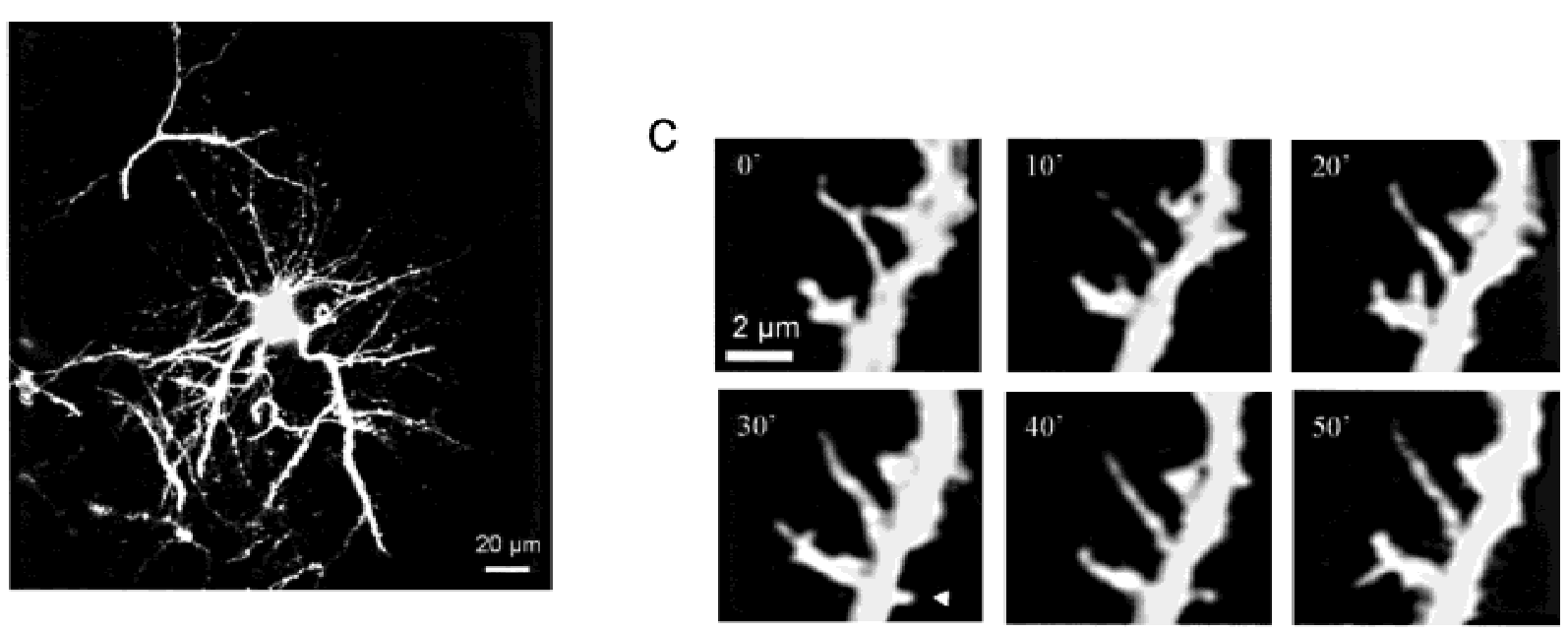

B
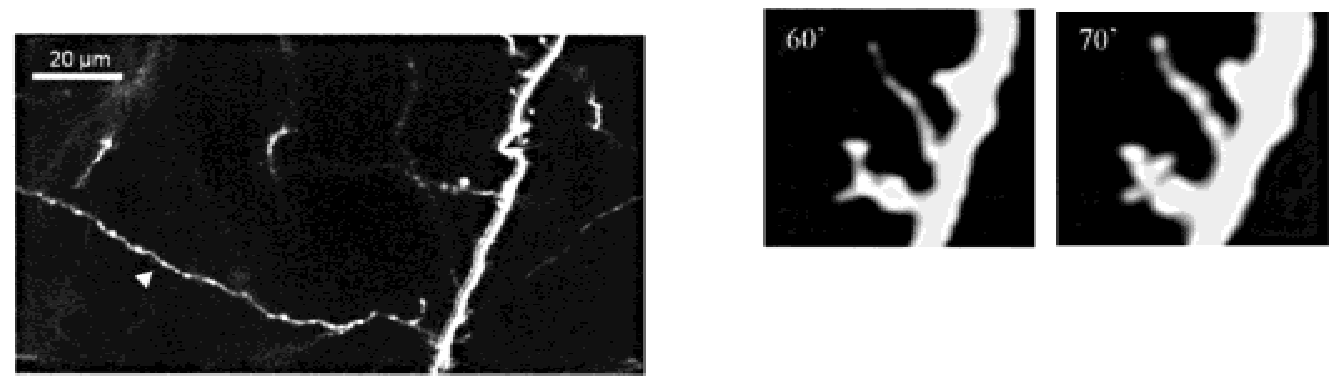

Figure 5 Imaging of recombinant Sindbis virus enhanced green fluorescent protein-infected neurons and processes in vivo. (A) Infected layer 2 neurons with basal dendrites (postnatal development [P] 11 rat; projection of 30 sections, 220-280 $\mu \mathrm{m}$ below the surface of the brain). (B) Axon (arrow head) approaching a dendrite (P 14 rat; single section, $200 \mu \mathrm{m}$ below the surface of the brain). (C) High-resolution image of dendritic morphological dynamics in vivo (projection of 15 sections, layer 2, P 9 rat; time stamps in minutes). Note growth of new protrusion (arrowhead).

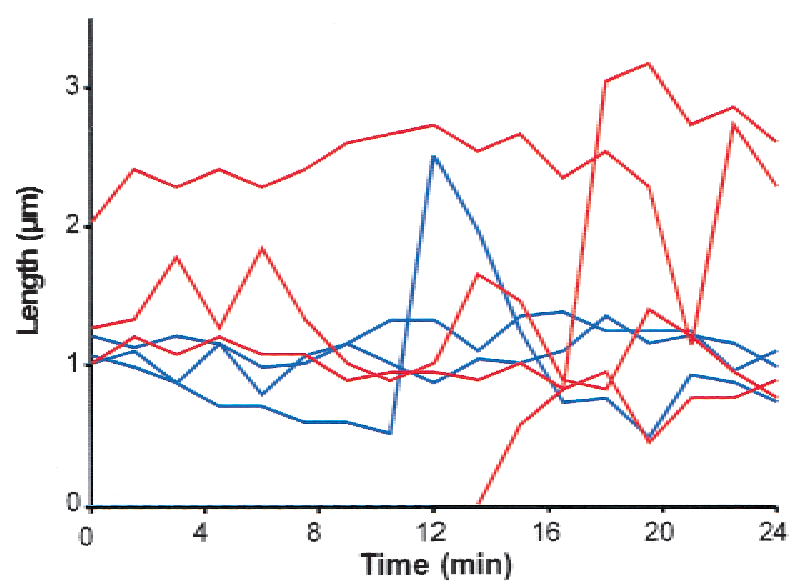

Figure 6 Rapid imaging in vivo and in vitro (90-sec intervals, postnatal day 13 rat). Spine lengths are plotted versus time (in vivo, red; in vitro, blue). Note emergence of new spine.

vealing a higher density of axonal processes. This is most likely due to diffusion of EGFP into the long axon collaterals rather than to growth of new axons, and hence may complicate a quantitative analysis of axonal morphogenesis. For example, it would take $25.5 \mathrm{~h}$ for EGFP (diffusion coefficient $8.7 \times 10^{-7} \mathrm{~cm}^{2} \mathrm{sec}^{-1}$ [Terry et al. 1995]) to diffuse through a 4-mm axon; this does not consider the expression time for a single molecule, up to $90 \mathrm{~min}$ (Tsien 1998). Therefore, the use of transgenic mice may be better suited for these long-term imaging studies.

\section{DISCUSSION}

We have shown that SIN-EGFP virus provides a powerful tool with which to label neocortical neurons for in vivo imaging. Viral labeling is substantially more efficient than introducing synthetic dyes with intracellular electrodes. Simple injection of SIN-EGFP leads to infection of groups of neurons. Focal injection of virus can lead to substantial infection distributed over up to $1 \mathrm{~mm}^{3}$ of tissue. The broad spatial distribution of infected neurons suggests that the virus is capable of infecting axons. Because layer 4 neurons have less long-ranging axonal arbors than do neurons in other layers (White 1989), this may explain the observation that distributions of infected neurons were less broad at the level of layer 4. A variable fraction of cells can be labeled in particular brain regions simply by titrating the concentration of the virus.

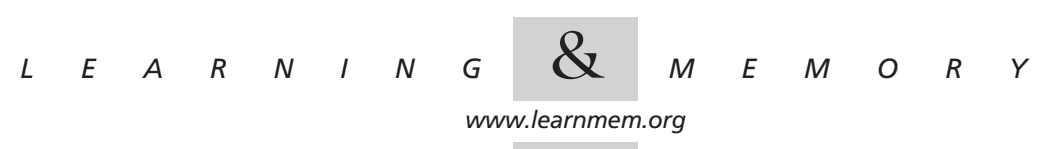



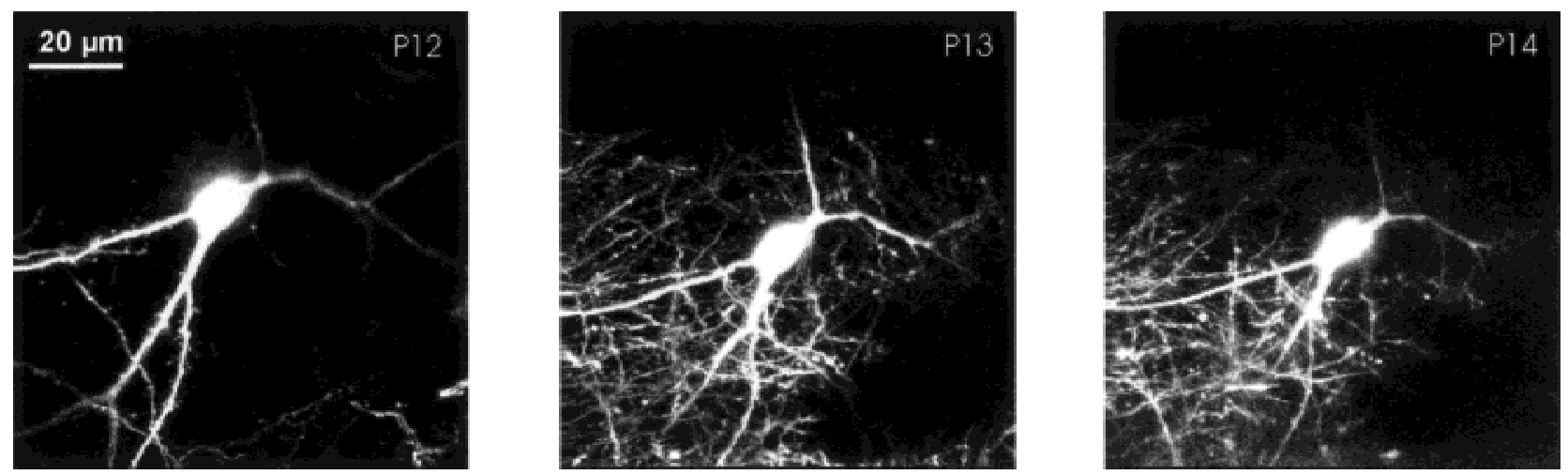

Figure 7 Chronic imaging of recombinant Sindbis virus enhanced green fluorescent protein-infected neurons in the somatosensory cortex in vivo. Postnatal day 12-14 rat, 1 to $3 \mathrm{~d}$ after infection. Note increase in labeled axon collaterals.

Infected neurons express high levels of EGFP and bright fluorescence in 1-photon microscopy and 2PLSM. Labeling appears to be limited to neurons, with no detectable labeling in glia, which is important for high-resolution, low background imaging. In contrast to previous studies that used other versions of GFP (Moriyoshi et al. 1996), but consistent with other studies that used EGFP (van den Pol and Ghosh 1998; Maletic-Savatic et al. 1999), the fluorescence signal appears to be homogeneously distributed throughout the neuron, labeling even tiny filopodia and dendritic spines. In contrast to a study that used transgenic mice expressing EGFP (van den Pol and Ghosh 1998), EGFP did not leak out in freshly cut slices, but maintained strong fluorescence throughout the life of the slice $(\sim 8 \mathrm{~h})$.

Our studies used a replication-defective virus, minimizing its neuropathological effects. For at least several days after infection, neurons maintained normal morphologies. In contrast to studies in cell cultures (Laakkonen et al. 1998), we did not see evidence for cytoskeletal rearrangements associated with expression of the viral protein NSP1. The cell culture studies differ from our in vivo studies in that they used very strong $\mathrm{T} 7$ promoters for expression of NSP1. This could account for the absence of effects of viral proteins on cell morphology in our studies. However, even with viral infection it is likely that some cytopathic effects develop over time, principally due to the high levels of foreign gene expression (Agapov et al. 1998). It has been shown that by using Sindbis variants specifically selected for producing lower levels of foreign gene expression (Agapov et al. 1998), long-term foreign gene expression without cytopathic effects should be possible. For studies that require gene expression over longer times than those tested here $(7 \mathrm{~d})$, such viral vectors might be preferable.

We also show that EGFP is well suited for in vivo 2PLSM imaging of neuronal morphology at the level of individual spines. This is primarily due to the brightness of EGFP under 2-photon excitation and the low photodamage levels associated with exciting EGFP. In vivo imaging of EGFP will be an extremely useful approach for studying morphogenesis in response to changes in the animal's experience (Lendvai et al. 2000).

To image aspects of cellular function beyond morphogenesis, it will be necessary to load neurons with fluorescent probes that are sensitive to the electrical or chemical environment of the cell. Fortunately, GFP-based functional indicators are becoming available. Probes that can detect membrane potential (Siegel and Isacoff 1997), $\mathrm{Ca}^{2+}$ concentration (Baird et al. 1999; Miyawaki et al. 1997), and vesicle exocytosis via $\mathrm{pH}$ sensing (Miesenbock et al. 1998) have been demonstrated. By using recombinant Sindbis virus it will be possible to introduce these indicators into neurons of interest.

Sindbis virus can also be directed to produce two heterologous proteins in parallel by separating their genes with internal ribosomal entry (IRES) sequences (Jang et al. 1988). This will allow labeling of neurons for high-resolution imaging with EGFP and at the same time will perturb their function by expressing transgenes in the same subset of neurons. By using IRES constructs together with ribozymebased strategies (Zhao and Lemke 1998), it should be possible to produce 'knock-outs' of genes in neurons that are also labeled with EGFP.

Transgenic mice expressing histochemical labels (Gustincich et al. 1997) or GFP (van den Pol and Ghosh 1998) provide an important tool for studying central nervous system development and anatomy. Particular promoters can be used to localize expression to specific brain regions (van den Pol and Ghosh 1998). However, viral techniques for labeling of neuronal populations have important advantages over transgenic mice. First, viruses can be applied to mammalian systems other than mice. Second, novel recombinant viruses such as Sindbis can easily be constructed and applied in a matter of weeks and at relatively low cost. Third, simply by varying viral titers it is possible to infect neurons at varying densities and numbers. These ad-

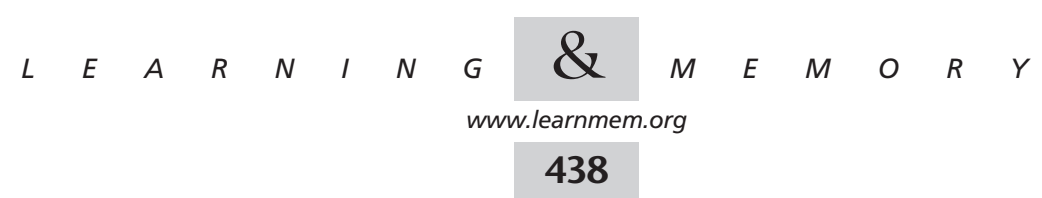


vantages are also important when using viruses to perturb neuronal function with transgenes.

\section{METHODS}

\section{Preparation of the pSinRep5-EGFP Vector}

The EGFP gene (derived from pEGFP-N1, Clontech) was cloned into the pSinRep5 plasmid (Invitrogen) (Malinow et al. 2000). The DNA was then linearized and used to produce RNA. The transcribed RNA lacks structural components of the virus; these are provided separately in a second transcription procedure with the helper virus plasmid (pDH). Baby hamster kidney (BHK) cells were transfected with both RNAs to generate replication defective SINEGFP pseudovirions. The virus was not further concentrated (concentration $\sim 10^{7}-10^{8} / \mathrm{ml}$ ).

\section{Infection of Neocortical Neurons In Vivo}

Albino (Sprague-Dawley) rats aged P8-P30 (or 1-8-wk-old mice [C57Bl/6]) were anesthetized by i.p. injection of ketamine/xylazine cocktail (ketamine: $0.56 \mathrm{mg} / \mathrm{g}$ body weight; xylazine: $0.03 \mathrm{mg} / \mathrm{g}$ body weight for P10-11 rats; slightly higher concentration for older animals). Anesthesia was supplemented as necessary. A glass pipette with a long shank was pulled and the tip was broken under a microscope to produce a 12- $\mu \mathrm{m}$ diameter tip. Pipettes were backfilled with the virus suspension. After placing the animal into a stereotaxic frame (Stoelting), an $\sim 0.5 \mathrm{~mm}$ diameter hole was burred into the skull over barrel cortex with a dental drill under guidance of a surgical microscope (Zeiss OpMi-1) and the dura was nicked. The injection pipette was lowered $\sim 700 \mu \mathrm{m}$ into the brain, avoiding visible damage to surface vasculature. As the pipette was slowly withdrawn, virus suspension (usually undiluted) was pressure-injected into the brain parenchyma in 6-10 puffs over $\sim 10 \mathrm{sec}$ (pulse duration $\sim 0.008 \mathrm{sec}$; pressure $\sim 30-40 \mathrm{psi}$; total volume $\sim 0.1 \mu \mathrm{L})$. The skin was then sutured.

\section{Preparation for Imaging}

At least $1 \mathrm{~d}$ after infection animals were anesthetized and their skull exposed. A titanium frame with a $6 \times 6-\mathrm{mm}$ hole was attached to the skull with dental cement. An $\sim 2 \times 2$-mm craniotomy was made around the injection hole and the dura was removed. The exposed brain was covered with $2.5 \%$ agarose in an artificial cerebrospinal fluid and 2-3 drops each of NeoDecadron and $0.3 \%$ gentamicin sulfate. A coverslide (No. 1.5) was placed over the agar and secured to the frame with screws. The metal frame was bolted to an optical bench to provide stability and minimize movement during the experimentation.

For chronic imaging experiments, a photograph of the exposed brain was taken with a digital camera before imaging. At the conclusion of the first imaging session, the printed image of the brain showing the surface vasculature was used to mark positions of the imaged neurons via the landmarks. Petroleum jelly was applied along the borders of the coverslide to seal a titanium plate that was then screwed onto the frame. On successive days of imaging, the plate was replaced with washers.

\section{Fluorescence Microscopy In Vitro}

After in vivo imaging, brains were either fixed or used to prepare fresh brain slices. For fixation, animals were perfused intracardially with saline and $4 \%$ formaldehyde. The brains were removed and kept in $4 \%$ formaldehyde for a week. They were then cut to $100-\mu \mathrm{m}$ thick slices by using a vibratome. Slices were then mounted onto gel-subbed slides by using Gel/Mount, an aqueous mounting medium with anti-fading agents (Biomedia Corp.) and coverslipped. Fluorescence of labeled neocortical neurons was imaged by using a $40 \times$ Zeiss objective and a Zeiss Axiophot microscope. Images were acquired by using a SPOT (Diagnostic Instruments Inc) cooled CCD camera or 2PLSM. For the SPOT camera, EGFP was excited by using a mercury arc lamp and fluorescence was collected by using a fluorescein filter set. In some cases fresh coronal brain slices were prepared in a similar way to those described (Mainen et al. 1999). For in vitro spine motility used in Figure 6 (inset), hippocampal slice cultures from $\mathrm{P} 7$ rat were biolistically transfected with EGFP under the CMV promoter (Lo et al. 1994), and imaged at 7 DIV. Fluorescence imaging of living slices was accomplished by using a 2PLSM microscope.

\section{2-Photon Laser Scanning Microscopy}

The in vivo 2PLSM imaging was achieved by using a custom-designed microscope. The microscope is based on a vertical rail (Newport, X-95) mounted on a motorized X-Y stage (NEAT, XYR 80-80). For maximal stability, the specimen was rigidly attached to the optical bench. As a light source we used a commercial Ti:sapphire laser (Tsunami, Spectra Physics) pumped by a 10 -W solid state laser (Millennia X, Spectra Physics). For EGFP imaging we set $\lambda \sim 910 \mathrm{~nm}$. The laser delivers $\sim 100$-fs pulses at a rate of $80 \mathrm{MHz}$. The power delivered to the objective varied greatly depending on the imaging depth (range 10-200 $\mathrm{mW}$ ). Before entering the microscope, the beam diameter was increased to $\sim 2 \mathrm{~mm}$ with a mirrorbased telescope. A pair of coupling mirrors was used to transfer the beam from the reference frame of the optical bench onto the $\mathrm{X}-\mathrm{Y}$ stage carrying the microscope and into a pair of scanning mirrors (6800, Cambridge Instruments). Each of the coupling mirrors moves with one direction of the stage; the result is that the beam remains aligned in the reference frame of the stage when the stage is moved. The scan mirrors were imaged into the backfocal plane of the objective ( $40 \times, 0.8 \mathrm{NA}$, Zeiss) by a scan lens (Zeiss) and the microscope tube lens (CVI); all of these components were chosen for best transmission in the near infrared. Fluorescence was detected through the objective, imaging the backfocal plane directly onto the photomultiplier tube (Hamamatsu, R3896) (whole-field detection). Image acquisition was achieved with custom software (Ray Stepnoski, Bell Laboratories, Lucent Technologies).

For brain-slice 2PLSM imaging, a modified confocal microscope (Olympus, Fluoview) was used. The microscope tube lens was replaced with a custom lens (CVI) with improved transmission at the excitation wavelength. The light source was similar to that described earlier. Fluorescence was detected through both objective and condenser in whole-field detection by using a pair of photomultiplier tubes. Photocurrents were summed by using custommade electronics.

In our experiments we detected only a subset of dendritic protrusions. The smallest structures were probably too dim to be detectable; others pointing up or downward from the dendrite were not resolvable because of the limited z-resolution $(\sim 2 \mu \mathrm{m})$ of our microscope. Hence, to compare spine numbers in preparations labeled with different methods, it is important to normalize the intensity of dendrites of comparable thickness to obtain images of comparable brightness. This was done for EGFP-Sindbis infected neurons imaged in vivo and in fixed tissue and DiO-labeled neurons in fixed tissue. Under our experimental conditions in vivo, signs of phototoxicity were almost completely absent, even after hours of nearly continuous imaging. Dendrites did not change in morphology or morphological dynamics in response to prolonged imaging,

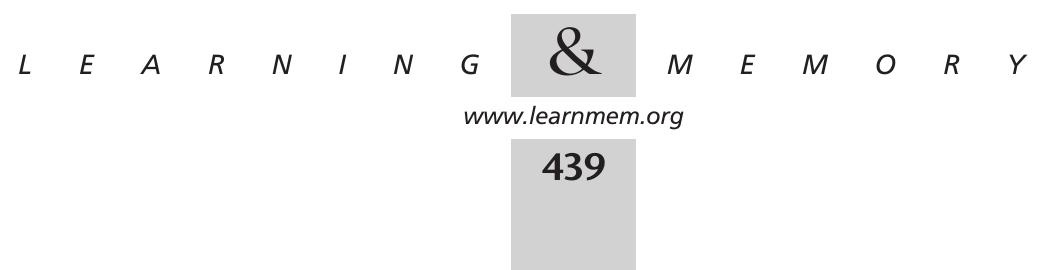


suggesting that phototoxicity did not perturb the results. Typically stacks of images of secondary and tertiary dendritic branches were collected at $\sim 10$-min intervals. Images were stored digitally and analyzed off-line by using custom software (written in IDL, Research Systems) essentially unprocessed. Careful review of z-projections and measurement analysis of $3 \mathrm{D}$ stacks helped to detect movement artifacts. The numbers and lengths of protrusions (lower limit $=0.4 \mu \mathrm{m})$ in a field of view $(170 \times 170 \mu \mathrm{m})$ were measured, keeping track of the fates of individual structures in optical sections.

\section{ACKNOWLEDGMENTS}

We thank the Malinow lab for help with viruses, Peter O'Brien and Adam Oberlander for technical assistance, and members of our laboratory for discussions. This work was supported by IBRO (B.L.), NIH (E.N., K.S.), HFSP (K.F. and K.S.), and Mathers, Pew and Whitaker Foundations (K.S.) and by an NIH training grant to SUNY Stony Brook (B.C.).

The publication costs of this article were defrayed in part by payment of page charges. This article must therefore be hereby marked "advertisement" in accordance with 18 USC section 1734 solely to indicate this fact.

\section{REFERENCES}

Agapov, E.V., Frolov, I., Lindenbach, B.D., Pragai, B.M., Schlesinger, S., and Rice, C.M. 1998. Noncytopathic Sindbis virus RNA vectors for heterologous gene expression. Proc. Natl. Acad. Sci. 95: 12989-12994.

Antonini, A. and Stryker, M.P. 1993. Rapid remodeling of axonal arbors in the visual cortex. Science 260: 1819-1821.

Bailey, C.H. and Kandel, E.R. 1993. Structural changes accompanying memory formation. Ann. Rev. Physiol. 55: 397-426.

Baird, G.S., Zacharias, D.A., and Tsien, R.Y. 1999 Proc. Natl. Acad. Sci. 96: 11241-11246.

Catalano, S.M., Robertson, R.T., and Killackey, H.P. 1995. Rapid alteration of thalamocortical axon morphology follows peripheral damage in the neonatal rat. Proc. Natl. Acad. Sci. 92: 2549-2552.

Chalfie, M., Tu, Y., Euskirchen, G., Ward, W.W., and Prasher, D.C. 1994. Green fluorescent protein as a marker for gene expression. Science 263: 802-805.

Cormack, B.P., Valdivia, R.H., and Falkow, S. 1996. FACS-optimized mutants of the green fluorescent protein (GFP). Gene 173: 33-38.

Corsini, J., Traul, D.L., Wilcox, C.L., Gaines, P., and Carson, J.O. 1996 Efficiency of transduction by recombinant Sindbis replicon virus varies among cell lines, including mosquito cells and rat sensory neurons. Biotechniques 21: 492-497.

Dailey, M.E. and Smith, S.J. 1996. The dynamics of dendritic structure in developing hippocampal slices. J. Neurosci. 16: 2983-2994.

Denk, W. and Svoboda, K. 1997. Photon upmanship: Why multiphoton imaging is more than a gimmick. Neuron 18: 351-357.

Denk, W., Strickler, J.H., and Webb, W.W. 1990. Two-photon laser scanning microscopy. Science 248: 73-76.

Desmond, N.L. and Levy, W.B. 1986. Changes in the numerical density of synaptic contacts with long-term potentiation in the hippocampal dentate gyrus. J. Comp. Neurol. 253: 466-475.

-1990. Morphological correlates of long-term potentiation imply the modification of existing synapses, not synaptogenesis, in the hippocampal dentate gyrus. Synapse 5: 139-143.

Diamond, M.E., Huang, W., and Ebner, F.F. 1994. Laminar comparison of somatosensory cortical plasticity. Science 265: 1885-1888.

Engert, F. and Bonhoeffer T. 1999. Dendritic spine changes associated with hippocampal long-term synaptic plasticity. Nature 399: 66-70.

Fiala, J.C., Feinberg, M., Popov, V., and Harris, K.M. 1998. Synaptogenesis via dendritic filopodia in developing hippocampal area CA1. J. Neurosci. 18: 8900-8911.

Fifkova, E. and Van Harreveld, A. 1977. Long-lasting morphological changes in dendritic spines of dentate granular cells following stimulation of the entorhinal area. J. Neurocytol. 6: 211-230.

Fischer, M., Kaech, S., Knutti, D., and Matus, A. 1998. Rapid actin-based plasticity in dendritic spines. Neuron 20: 847-854.

Fox, K. 1992. A critical period for experience-dependent synaptic plasticity in rat barrel cortex. J. Neurosci. 12: 1826-1838.

Gähwiler, B.H., Capogna, M., Debanne, D., McKinney, R.A., and Thompson, S.M. 1997. Organotypic slice cultures: A technique has come of age. Trends Neuro. 20: 471-477.

Glazewski, S. and Fox, K. 1996. Time course of experience-dependent synaptic potentiation and depression in barrel cortex of adolescent rats. J. Neurosci. 75: 1714-1729.

Greenough, W.T., Hwang, H.M., and Gorman, C. 1985. Evidence for active synapse formation or altered postsynaptic metabolism in visual cortex of rats reared in complex environments. Proc. Natl. Acad. Sci. 82: 4549-4552.

Gustincich, S., Feigenspan, A., Wu, D.K., Koopman, L.J., and Raviola, E. 1997. Control of dopamine release in the retina: A transgenic approach to neural networks. Neuron 18: 723-736.

Gwag, B.J., Kim, E.Y., Ryu, B.R., Won, S.J., Ko, H.W., Oh, Y.G., Chu, Y.G., Ha, S.J., Sung, Y.C., et al. 1998. A neuron-specific gene transfer by a recombinant defective sindbis virus. Brain Res. Mol. Brain Res. 63: 53-61.

Harris, R.M. and Woolsey, T.A. 1981. Dendritic plasticity in mouse barrel cortex following postnatal vibrissa follicle damage. J. Comp. Neurol. 196: 357-376.

Heim, R. and Tsien, R.Y. 1996. Engineering green fluorescent protein for improved brightness, longer wavelengths and fluorescence energy transfer. Curr. Biol. 6: 178-182.

Jang, S.K., Krausslich, H.G., Nicklin, M.J., Duke, G.M., Palmenberg, A.C., and Wimmer, E. 1988. A segment of the 5' nontranslated region of encephalomyocarditis virus RNA directs internal entry of ribosomes during in vitro translation. J. Virol. 62: 2636-2643.

Katz, L.C. and Shatz, C.J. 1996. Synaptic activity and the construction of cortical circuits. Science 274: 1133-1138.

Kleinschmidt, A., Bear, M.F., and Singer, W. 1987. Blockade of NMDA receptors disrupts experience-dependent plasticity of kitten striate cortex. Science 238: 355-358.

Laakkonen, P., Auvinen, P., Kujala, P., and Kaariainen, L. 1998. Alphavirus replicase protein NSP1 induces filopodia and rearrangement of actin filaments. J. Virol. 72: 10265-10269.

Lendvai, B., Stern, E.A., Chen, B., and Svoboda, K. 2000. Experience-dependent plasticity of dendritic spines in the developing rat barrel cortex in vivo. Nature 404: 876-881.

Lo, D.C., McAllister, A.K., and Katz, L.C. 1994. Neuronal transfection in brain slices using particle-mediated gene transfer. Neuron 13: $1263-1268$.

Mainen, Z.F., Maletic-Savatic, M., Shi, S.H., Hayashi, Y., Malinow, R., and Svoboda, K. 1999. Two-photon imaging in living brain slices. Methods 18: 231-239.

Maletic-Savatic, M., Malinow, R., and Svoboda, K. 1999. Rapid dendritic morphogenesis in CA1 hippocampal dendrites induced by synaptic activity. Science 283: 1923-1927.

Malinow, R., Hayashi, Y., Maletic-Savatic, M., Zaman, S., Poncer, J.C., Shi, S.H., Esteban, J.E., 2000. Introduction of green fluorescent protein into hippocampal neurons through viral infection. In Imaging Neurons (ed. R. Yuste, F. Lanni, and A. Konnerth), pp. 58.1-58.8. Cold Spring Harbor Press, Cold Spring Harbor, NY.

McAllister, A.K., Lo, D.C., and Katz, L.C. 1995. Neurotrophins regulate dendritic growth in developing visual cortex. Neuron 15: 791-803.

McAllister, A.K., Katz, L.C., and Lo, D. 1996. Neurotrophin regulation of cortical dendritic growth requires activity. Neuron 17: 1057-1064.

. 1997. Opposing roles for endogenous BDNF and NT-3 in regulating cortical dendritic growth. Neuron 18: 767-778.

Miesenbock, G., Angelis, D.A.D., and Rothman, J.E. 1998. Visualizing secretion and synaptic transmission with $\mathrm{pH}$-sensitive green fluorescent proteins. Nature 394: 192-195.

Miyawaki, A., Llopis, J., Heim, R., McCaffery, J.M., Adams, J.A., Ikura, M.,

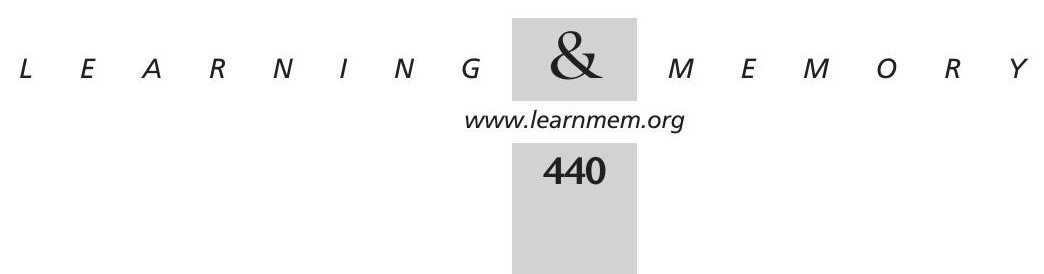


and Tsien, R.Y. 1997. Fluorescence indicators for $\mathrm{Ca}^{2+}$ based on green fluorescent proteins and calmodulin. Nature 388: 882-887.

Moriyoshi, K., Richards, L.J., Akazawa, C., O'Leary, D.D.M., and Nakanishi, S. 1996. Labeling neural cells using adenoviral gene transfer of membrane-targeted GFP. Neuron 16: 255-260.

O'Malley, Kao, Y.-H., and Fetcho, J.R. 1996. Imaging the functional organization of zebrafish hindbrain segments during escape behaviors. Neuron 17: 11145-11155.

Pettit, D.L., Koothan, T., Liao, D., and Malinow, R. 1995. Vaccinia virus transfection of hippocampal slice neurons. Neuron 14: 685-688.

Pierce, D.W., Hom-Booher, N., and Vale, R.D. 1997. Imaging individual green fluorescent proteins. Nature 388: 338.

Potter, S.M., Wang, C.M., Garrity, P.A., and Fraser, S.E. 1996. Intravital imaging of green fluorescent protein using two-photon laser-scanning microscopy. Gene 173: 25-31.

Saito, Y., Murakami, F., Song, W.J., Okawa, K., Shimono, K., and Katsumara, H. 1992. Developing corticorubal axons of the cat form synapses on filopodial dendritic protrusions. Neurosci. Lett. 147: 81-84.

Siegel, M.S. and Isacoff, E.Y. 1997. A genetically encoded optical probe of membrane voltage. Neuron 19: 735-741.

Sorra, K.E. and Harris, K.M. 1998. Stability in synapse number and size at $2 \mathrm{hr}$ after long-term potentiation in hippocampal area CA1. $J$. Neurosci. 18: 658-671.

Svoboda, K., Denk, W., Kleinfeld, D., and Tank, D.W. 1997. In vivo dendritic calcium dynamics in neocortical pyramidal neurons. Nature 385: 161-165.

Svoboda, K., Helmchen, F., Denk, W., and Tank, D.W. 1999. The spread of dendritic excitation in layer $2 / 3$ pyramidal neurons in rat barrel cortex in vivo. Nature Neurosci. 2: 65-73

Svoboda, K., Tank, D.W., Stepnoski, R., and Denk, W. 2000. Two-photon imaging of neuronal function in neocortex in vivo. In Imaging Neurons (ed. R. Yuste, F. Lanni, and A. Konnerth), pp. 22.1-22.11. Cold Spring Harbor Press, Cold Spring Harbor, NY.
Terry, B.R., Matthews, E.K., and Haseloff, J. 1995. Molecular characterisation of recombinant green fluorescent protein by fluorescence correlation microscopy. Biochem. Biophys. Res. Commun. 217: 21-27.

Tsien, R. 1998. The green fluorescent protein. Annu. Rev. Biochem. 67: 509-544.

van den Pol, A.N. and Ghosh, P.K. 1998. Selective neuronal expression of green fluorescent protein with cytomegalovirus promoter reveals entire neuronal arbor in transgenic mice. J. Neurosci. 18: $10640-10651$.

Van Harreveld, A. and Fifkova, E. 1975. Swelling of dendritic spines in the fascia dentata after stimulation of the perforant fibers as a mechanism of post-tetanic potentiation. Exp. Neurol. 49: 736-749.

White, E.L. 1989. Cortical circuits. Birkhauser, Boston, MA

Wiesel, T.N. 1982. The postnatal development of the visual cortex and the influence of development. Nature 299: 583-591.

Xu, C., Zipfel, W., Shear, J.B., Williams, R.M., and Webb, W.W. 1996. Multiphoton fluorescence excitation: New spectral windows for biological nonlinear microscopy. Proc. Natl. Acad. Sci. 93: 10763-10768.

Yuste, R. and Katz, L.C. 1991. Control of postsynaptic $\mathrm{Ca}^{2+}$ influx in developing neocortex by excitatory and inhibitory neurotransmitters. Neuron 6: 333-344.

Zhao, J.J. and Lemke, G. 1998. Selective disruption of neuregulin-1 function in vertebrate embryos using ribozyme-tRNA transgenes. Development 125: 1899-1907.

Ziv, N.E. and Smith, S.J. 1996. Evidence for a role of dendritic filopodia in synaptogenesis and spine formation. Neuron 17: 91-102.

Received April 18, 2000; accepted in revised form September 21, 2000. 


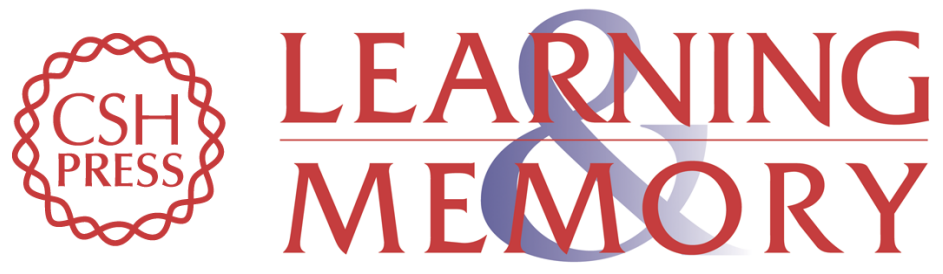

\section{Imaging High-Resolution Structure of GFP-Expressing Neurons in Neocortex In Vivo}

Brian E. Chen, Balazs Lendvai, Esther A. Nimchinsky, et al.

Learn. Mem. 2000, 7:

Access the most recent version at doi:10.1101/lm.32700

References This article cites 56 articles, 20 of which can be accessed free at: http://learnmem.cshlp.org/content/7/6/433.full.html\#ref-list-1

License

Email Alerting Receive free email alerts when new articles cite this article - sign up in the box at the Service top right corner of the article or click here. 